\title{
Infertile or childless by choice? A multipractice survey of women aged 35 and 50
}

\author{
GINA JOHNSON, DELYTH ROBERTS, RICHARD BROWN, ELIZABETH COX, \\ ZYG EVERSHED, PRAVIN GOUTAM, PAUL HASSAN, RUTH ROBINSON, \\ ASHOK SAHDEV, KATHY SWAN, CATHY SYKES
}

\begin{abstract}
Eleven general practitioners examined the medical records of all women on their lists born in 1950 (617 patients) and 1935 (533 patients) to determine the prevalence of childlessness and specialist consultations about infertility.

Eighty eight (14.3\%) of the women born in 1950 and $41(7 \cdot 7 \%)$ of those born in 1935 were childless. Sixty eight women born in 1950 $(11.0 \%)$ and 17 born in $1935(3.2 \%)$ were considered childless by choice. Involuntary childlessness was found in $20(3.3 \%)$ of the women born in 1950 and $24(4.5 \%)$ born in 1935 . Forty two (6.8\%) of the women born in 1950 had consulted a specialist about infertility as compared with 19 (3.6\%) born in 1935 .

This study found a significant increase in voluntary childlessness among the younger women; there was no evidence of a change in the prevalence of involuntary childlessness despite the increasing demand for specialist referral, which appeared to be made by women who were parous or destined to become so.
\end{abstract}

\section{Introduction}

The French demographer Henri Leridon wrote in 1977: "Our knowledge of sterility remains very imprecise. It is based on few observations, all from historical populations; and the spread of contraception has made observations on contemporary populations nearly impossible." Southam estimated from a mathematical model in 1960 that $10 \%$ of married couples would ultimately be infertile, and that paper is widely quoted. ${ }^{2}$ Kiser $e t$ al reported that the figure was below $8 \%$, but their American population study included a large number of "surgically sterile" women. ${ }^{3}$

Life table analysis of cumulative conception rates does not permit an estimate of end infertility (as defined by the failure to produce a living child throughout the reproductive life) because it includes couples lost to follow up during the period under study..$^{46}$ There is no reliable information on end infertility, and therefore for this study we selected women born in 1935, who were at the end of their reproductive lives, and compared them with those born in 1950, most of whom would have made their decisions on childbearing, in order to study the changing patterns of childlessness.

It is generally accepted that failure to conceive after one year without contraception warrants specialist referral and the proportion of couples to whom this applies is variously estimated as 10$27 \% .{ }^{2}{ }^{4} 7$ That some couples might choose to remain childless was

South Bedfordshire Practitioners' Group

GINA JOHNSON, MB, MRCGP, general practitioner

DELYTH ROBERTS, MB, MRCGP, general practitioner

RICHARD BROWN, MB, MRCGP, general practitioner

ELIZABETH COX, MB, MRCGP, general practitioner

ZYG EVERSHED, MB, MRCGP, general practitioner

PRAVIN GOUTAM, MB, BA, general practitioner

PAUL HASSAN, MB, MRCGP, general practitioner

RUTH ROBINSON, $M B$, BS, general practitioner

ASHOK SAHDEV, MB, DRCOG, general practitioner

KATHY SWAN, MB, CHB, general practitioner

CATHY SYKES, MB, DRCOG, general practitioner

Correspondence to: Dr G M Johnson, 26 Ashcroft Road, Luton LU2 9AU. not considered in the early studies but has recently been examined in one British and several American reports. ${ }^{8-10}$ The American papers consist mainly of statistical projections, and the British one is concerned with attitudes rather than numbers. There are no published British data on the prevalence of voluntary infertility. The aim of this study was therefore to collect statistics from a large general practice population on the prevalence of childlessness (voluntary and involuntary) and referral rates to infertility specialists in women aged 35 and 50.

\section{Subjects and methods}

Between November 1985 and January 1986 we examined the age-sex registers of our 10 practices (combined list of 101100 ) located in Luton, Dunstable, and Leighton Buzzard and obtained the names of all women born in 1950 and 1935. These patients' medical records were then examined and the following information extracted: numbers of live births, stillbirths, miscarriages, and terminations; if the woman was childless, whether there was firm evidence that this was voluntary-that is, current use of contraception, sterilisation of self or partner, or a written comment in the records; and any record of a consultation with a specialist about infertility.

After collecting these data we discovered a considerable number of childless women who could not be classified on the above criteria. They had not been seen by a specialist in infertility, nor had they written evidence of being childless by choice. In an attempt to improve the accuracy of our figures we therefore broadened our definitions of the two categories. We defined a woman who had chosen, for whatever reason, not to test her fertility as "voluntarily childless" and a woman who had presented her childlessness as a problem (to either her general practitioner or a specialist in infertility) as "infertile.". We then examined the notes of our unclassified group again. In a few cases items of information in the medical records helped with classification; in other instances we questioned the patients casually during a routine consultation or attendance for a cervical smear (several patients were recalled for a smear during the study because they were found to be overdue for this test when the notes were examined). There still remained some women who could not be classified, however, and we therefore assumed that the ratio of infertile to voluntarily childless was the same in the unclassified group as in the classified group.

Proportions were compared by the $\mathrm{z}$ test.

\section{Results}

\section{WOMEN BORN IN 1950}

A total of 748 women born in 1950 (aged 35 at time of study) were identified from the age-sex registers. Of these, 131 had insufficient data for the following reasons: newly registered; patient had emigrated; patient's name had been changed in record but not on index card; notes were incomplete. There was no reason to suppose that this group differed significantly from those for whom we had information and they were not considered further.

Of the 617 patients for whom data were complete, $88(14 \cdot 3 \%)$ had not delivered a living child (table I). Forty two $(6 \cdot 8 \%)$ had consulted a specialist about infertility, of whom 18 remained childless. Forty nine were regarded as voluntarily childless by our original criteria. One patient who had attended a fertility clinic and subsequently conceived, however, changed her mind and had the pregnancy terminated. She was therefore removed from the infertile group and added to the voluntarily childless group.

There remained 21 patients who could not initially be classified. Two of these attended for cervical smears and stated that they were childless by choice. Further examination of the medical records disclosed two single 
women who had recently been found to have their hymens intact, two single women who were severely mentally retarded, and a divorced woman who had had three terminations of pregnancy. These were all included in the voluntarily childless group on the grounds that they had chosen not to test their fertility. This brought the voluntarily childless total to 57 patients $(9 \cdot 2 \%)$ and the infertile total to $17(2 \cdot 8 \%)$. The remaining 14 patients $(2 \cdot 3 \%)$ were unclassified (table II).

If we assume that the ratio of infertility to voluntary childlessness was the same in the unclassified and classified groups the prevalence of voluntary childlessness was $(57 \times 88) /(74 \times 617) \times 100=11.0 \%$ and of infertility $(17 \times$ $88) /(74 \times 617) \times 100=3.3 \%$ in women aged 35 (table III).

TABLE I-Numbers of women aged 35 and 50 identified from age-sex registers and proportions of those with complete data who were childless or had sought help for infertility

\begin{tabular}{|c|c|c|c|c|c|}
\hline Year of birth & $\begin{array}{l}\text { Total on } \\
\text { age-sex } \\
\text { registers }\end{array}$ & $\begin{array}{l}\text { No with } \\
\text { insufficient } \\
\text { data }\end{array}$ & $\begin{array}{l}\text { No with } \\
\text { complete data }\end{array}$ & $\begin{array}{c}\text { No }(\%) \\
\text { childless }\end{array}$ & $\begin{array}{l}\text { No }(\%) \text { who } \\
\text { had consulted } \\
\text { infertility } \\
\text { specialist }\end{array}$ \\
\hline $\begin{array}{l}1950 \\
1935\end{array}$ & $\begin{array}{l}748 \\
.621\end{array}$ & $\begin{array}{r}131 \\
88\end{array}$ & $\begin{array}{l}617(100 \%) \\
533(100 \%)\end{array}$ & $\begin{array}{l}88(14 \cdot 3) \\
41(7 \cdot 7)\end{array}$ & $\begin{array}{l}42(6 \cdot 8) \\
19(3 \cdot 6)\end{array}$ \\
\hline Significance & & & & $\begin{array}{l}p=0.01 \\
z=-3.522\end{array}$ & $\begin{array}{l}\mathrm{p}=0.05 \\
\mathrm{z}=-2.452\end{array}$ \\
\hline
\end{tabular}

TABLE II-Distribution of voluntary childlessness and infertility among women who had never delivered a living child

\begin{tabular}{lcccc}
\hline & $\begin{array}{c}\text { No }(\%) \\
\text { voluntarily } \\
\text { childless }\end{array}$ & No(\%) infertile & $\begin{array}{c}\text { No (\%) } \\
\text { unclassified }\end{array}$ & No (\%) overall \\
\hline $1950(\mathrm{n}=617)$ & $57(9 \cdot 2)$ & $17(2 \cdot 8)$ & $14(2 \cdot 3)$ & $88(14 \cdot 3)$ \\
$1935(\mathrm{n}=533)$ & $10(1 \cdot 9)$ & $14(2 \cdot 6)$ & $17(3 \cdot 2)$ & $41(7 \cdot 7)$ \\
\hline Significance & $\mathrm{p}=0.01$ & $\mathrm{NS}$ & $\mathrm{NS}$ & \\
& $\mathrm{z}=-5 \cdot 316$ & $\mathrm{z}=-0 \cdot 134$ & $\mathrm{z}=0.961$ & \\
\hline
\end{tabular}

TABLE III-Estimated voluntary childlessness and infertility among women who had never delivered a living child

\begin{tabular}{cccc}
\hline Year of birth & $\begin{array}{c}\text { No(\%) estimated } \\
\text { voluntarily childless }\end{array}$ & $\begin{array}{c}\text { No (\%) estimated } \\
\text { infertile }\end{array}$ & No(\%) overall \\
\hline $1950(\mathrm{n}=617)$ & $\begin{array}{l}68(11 \cdot 0) \\
17(3 \cdot 2)\end{array}$ & $\begin{array}{l}20(3 \cdot 3) \\
24(4 \cdot 5)\end{array}$ & $\begin{array}{c}88(14 \cdot 3) \\
41(7 \cdot 7)\end{array}$ \\
\hline $1935(\mathrm{n}=533)$ & $\mathrm{p}=0.01$ & $\mathrm{NS}$ & \\
\hline Significance & $\mathrm{z}=-4.983$ & $\mathrm{z}=1 \cdot 111$ & \\
&
\end{tabular}

\section{WOMEN BORN IN 1935}

Out of 621 women born in 1935 (aged 50 at time of study) who were identified from the age-sex registers, 88 had insufficient data and were not considered further. The remaining 533 patients included $41(7 \cdot 7 \%)$ who had never delivered a living child (table I). Nineteen (3.6\%) had consulted a specialist about infertility, of whom 11 remained childless. Seven were regarded as voluntarily childless by our original criteria. The remaining 23 childless patients could not initially be classified. Of four of these who attended for cervical smears, two told us that they were childless by choice and one married woman was found to have an intact hymen. These three were added to the voluntarily childless group on the grounds that they had chosen not to test their fertility. The remaining patient told us that she had consulted her general practitioner about infertility but was not referred to a specialist.

Examination of the medical records of the remainder disclosed another patient who had consulted her general practitioner about infertility but was not referred, and one whose husband had become impotent. These were added to the infertile group on the grounds that they had presented their infertility as a problem. This brought the voluntarily childless total to 10 women $(1 \cdot 9 \%)$ and the infertile total to $14(2 \cdot 6 \%)$. The remaining 17 women were unclassified (table II).

If we assume that the ratio of infertility to voluntary childlessness was the same in the unclassified and classified groups the prevalence of voluntary childlessness in women aged 50 was $(10 \times 41) /(24 \times 533) \times 100=3 \cdot 2 \%$ and of infertility $(14 \times 41) /(24 \times 533) \times 100=4 \cdot 5 \%$ (table III).

\section{Discussion}

To approach the question of childlessness from the standpoint of general practice should, in theory, produce more accurate estimates of fertility statistics than could be obtained from infertility clinics or statistical projections. It would not be possible to organise a sufficiently large general practice study without the cooperation of several practices with age-sex registers, though our results highlight the limitations of the age-sex register as a research tool because of its preponderance of inaccurate entries. ${ }^{.1}$

The obvious method of collecting population data on childlessness is by patient questionnaire, as used in several American studies. ${ }^{8} 9$ We were reluctant to use this technique, however, as we thought that unsolicited probing into such a sensitive matter might cause our patients considerable distress and that the replies might well be inaccurate. Our experience in completing cervical smear forms shows how often women "forget" an adopted illegitimate child or termination of pregnancy in this setting. The other problem with questionnaires is that of deciding whether the non-responders form an atypical group. These difficulties can be overcome by studying general practice records, which should hold complete documentation of all pregnancies, fertility studies, and contraception. We recognise, however, that our records are not perfect and that occasionally women may receive private treatment-for example, termination of pregnancy or infertility investigations-without their general practitioner's knowledge.

Accurate demographic data cannot be collected from a fertility clinic because of the difficulty in estimating the size of the population from which patients are drawn; nevertheless, we know that the proportion of women seeking help about infertility is increasing, ${ }^{12}$ recent estimates varying from $7 \%^{12}$ to $17 \%$ of the population. Our figure of $6.8 \%$ supports the lower estimate. The figure of $17 \%$ was obtained by Hull et al, who calculated the incidence of problems with infertility (as defined by presentation at a specialist clinic) in a single health district in 1982-3. ${ }^{13}$ This high incidence may reflect the effect of local availability of an established fertility clinic and recent increases due to patients' awareness of advances in treatment. Our statistics suggest that the increase in demand for referral about infertility is due to an increased attendance of women who eventually become parous. They do not distinguish between those patients who attended the clinic because of secondary infertility and those who were childless when they attended but subsequently bore children.

The proportion of women of menopausal age who were childless $(7 \cdot 7 \%)$ was lower than expected from other studies, ${ }^{14}{ }^{15}$ especially as our population included single women without sexual experience, whereas most previous work examined only married women. Childlessness was considerably more common in the younger age group $(14.3 \%)$, largely due to the remarkable increase in voluntary childlessness, which we estimated to be the case in $11 \%$ of our 35 year olds. This increase presumably reflects the comparatively recent availability of effective contraception and improved career opportunities for women.

We cannot predict how many of the childless women aged 35 were delaying starting their families as opposed to choosing to remain permanently without children. Accurate statistics are surprisingly difficult to obtain. The Office of Population Censuses and Surveys does not keep parity data for illegitimate births, but the figures show that of all married women having their first live birth in 1985, only $3.7 \%$ were aged 35 and over. ${ }^{16}$ We think that including illegitimate births would probably reduce this figure. Local statistics show that of all 1438 primigravidas booking at the Luton and Dunstable Hospital in 1986, $35(2 \cdot 4 \%)$ were aged 35 and over (M Lobb, personal communication). As the patterns of childlessness appear to be changing it is not possible to make a direct comparison between these figures, which include pregnant women of all ages, and those which estimate the prevalence of childlessness in one age group. For 
similar reasons we thought that it would not be helpful to go back to our records of the women aged 50 to establish how many of these had delayed their first live birth until the age of 35 and over, as they formed such a different group from our current 35 year olds.

The difficulty in classifying voluntarily childless women has been considered elsewhere. ${ }^{8} \mathrm{~A}$ woman's perception of her childless state may well alter during her reproductive life. She may be "infertile" during one liaison but "childless by choice" in another; she may leave conception to chance without pursuing the option of treatment; or she may declare her childlessness, in retrospect, to be voluntary in order to avoid the stigma of infertility.

We were intrigued by the group of childless women who were not using prescribed contraception but had never sought help for infertility. Possible reasons include $(a)$ no established sexual relationship (including non-consummation of marriage); (b) voluntarily childlessness, using non-prescription methods successfully; (c) a partner who had already had a vasectomy in a previous relationship; $(d)$ sexual problems, including impotence of a partner; (e) too ashamed or embarrassed to seek help for infertility. It was noticeable that this group contained many patients who did not often consult their doctors.

The presence of this unclassified group means that our estimates of infertility and voluntary childlessness are necessarily imprecise; even if we had more information women in some of the above categories would be difficult to classify. Our method of dividing this group (in the same proportions as those for whom the reason for childlessness was known) is open to question, but it produced figures for the two age groups which could conveniently be compared.

A recent paper concluded that infertility is becoming more prevalent. ${ }^{12}$ Despite the large increase which we found in the proportion of women aged 35 who were childless compared with those aged 50, and the increase in the number of women requesting specialist consultations for infertility, we found no evidence of an increase in involuntary childlessness - that is, due to infertility. Our range of $3 \cdot 3 \%$ to $4.5 \%$ is much lower than the $8-10 \%$ predicted by previous statistical projections.

The number of women who chose to remain childless greatly increased during the study period; we estimate that they accounted for one in nine of all 35 year olds. This figure has not been measured in any previous British report, though there are some American data. ${ }^{17}$ Another recent paper states: "It is estimated that $12 \%$ of couples are childless. In the great majority of cases they consult their gynecologist for advice and therapy." five of our childless 35 year old women had ever consulted a specialist about infertility disputes this. We submit that the significant increase in voluntary childlessness which we have documented is a factor of considerable importance in examining fertility statistics.

We thank Mr M O Lobb for invaluable help in searching published work and drafting the final article; Mrs Peter Martin, secretary of the Beds and Herts Faculty of the Royal College of General Practitioners, for secretarial work; Dr E Martin and Mr M Hull for advice and encouragement; and the staff of our various practices for retrieving the names and records. Our thanks are also due to Mr A Perkins and Ms N Saragoussi, of the North West Thames Regional Health Authority, for help with the statistical analysis.

\section{References}

1 Leridon H. Human fertility, the basic components. Chicago: University of Chicago Press, 1977.

2 Southam AL. What to do with the "normal" infertile couple. Fertil Steril 1960;11:543-9.

3 Kiser CV, Grabill WH, Campbell AA. Trends and variations in fertility in the United States. Cambridge, Mass: Harvard University Press, 1968.

4 Barnea ER, Holford TR, McInnes DRA. Long-term prognosis of infertile couples with normal basic investigations: a life-table analysis. Obstet Gynecol 1985;66:24-6.

5 Cooke ID, Sulaiman RA, Lenton EA, Parsons RJ. Fertility and infertility statistics: their importance and application. Clin Obstet Gynecol 1981;8:531-48.

6 Tietze C. Fertility after discontinuation of intrauterine and oral contraception. Int $\mathcal{J}$ Fertil 1968;13:4:385-9.

7 Tietze C. Statistical contributions to the study of human fertility. Fertil Steril 1956;7:88-95.

8 Poston DL, Kramer KB, Trent K, Yu MY. Estimating voluntary and involuntary childlessness in the developing countries. F Biosoc Sci 1983;15:441-52.

9 Bloom DE, Trussell J. What are the determinants of delayed childbearing and permanent childlessness in the United States? Demography 1984;21:591-611.

10 Baum FE. Orientations towards voluntary childlessness. F Biosoc Sci 1983;15:153-64.

11 Sheldon MG, Rector AL, Barnes PA. The accuracy of age-sex registers in general practice. f R Coll Gen Pract 1984;34:269-71.

12 Aral SO, Cates W. The increasing concern with infertility-Why now? JAMA 1983;250:2327-31.

13 Hull MGR, Glazener CMA, Kelly NJ, et al. Population study of causes, treatment and outcome of infertility. BrMed f 1985;291:1693-7.

14 Jensen P. Childlessness and general practice. $f$ R Coll Gen Pract 1966;11:150-65.

15 Titmuss RM, Grundy F. Childlessness and the small family-a fertility study in Luton. Lancet 1946;ii:687-90.

16 Office of Population Censuses and Surveys. Birth statistics 1985 (England and Wales). London: HMSO, 1986.

17 Pebley AR, Bloom DE. Childless Americans. American Demography 1982;4:18-21.

(Accepted 5 February 1987)

\section{Patients, methods, and results}

We studied 20 consecutive adults (mean age 57 (range 36-73); 17 men, three women) during routine cardiac catheterisation. They continued taking their usual drugs, and premedication comprised oral diazepam with $5-10 \mathrm{mg}$ diazepam and $12.5 \mathrm{mg}$ prochlorperazine given intravenously five minutes before the procedure. After arterial cannulation the systemic arterial pressure tracing and electrocardiogram were recorded continuously. The baseline reading was taken as that over 30-60 seconds, and then $200 \mu \mathrm{g}$ thyrotrophin releasing hormone was given intravenously over 15 seconds. We then continued recording for at least two minutes. Subsequent haemodynamic and angiographic recordings were made according to our standard practice.

Systolic and diastolic blood pressure, heart rate, and rate-pressure product were taken as the average over 10 consecutive beats during the baseline period and at peak response (figure). Mean systolic pressure rose by $17 \%$ from $121 \cdot 8$ (SD $19 \cdot 1$ ) to $142 \cdot 6(24 \cdot 0) \mathrm{mm} \mathrm{Hg}$ (range 9-43) and diastolic pressure by $20 \%$ from $64 \cdot 2$ $(7 \cdot 3)$ to $76.9(9 \cdot 5) \mathrm{mm} \mathrm{Hg}$ (range $3-25$ ). Mean heart rate rose by $12 \%$ from 63.5
$(15.0)$ to $70.6(15.0)$ beats/min (range 1-17) and the mean rate-pressure product by $31 \%$ from $7 \cdot 6(1 \cdot 6) \times 10^{3}$ to $10 \cdot 0(2 \cdot 3) \times 10^{3}$ beats. $\mathrm{mm} \mathrm{Hg} / \mathrm{min}$ (range $0 \cdot 3-5 \cdot 3 \times$ $\left.10^{3}\right)$. All changes were significant $(\mathrm{p}<0.001$, paired $t$ test). The rate-pressure product was maximum at a mean of 56 seconds (range 21-98) after administration of thyrotrophin releasing hormone and returned to baseline values within two to five minutes. There were no electrocardiographic changes or ischaemic symptoms.

Nine patients were taking $\beta$ blockers, eight calcium antagonists, seven nitrates, four diuretics, two digoxin, one methyldopa, and one amiodarone; three were not taking any drugs. Angiography showed coronary artery disease in 16 patients (triple vessel disease in six, double vessel disease in eight, and single vessel disease in two) and aortic valve disease in two. Baseline thyroid function was normal in all, including one patient taking thyroxine $50 \mu \mathrm{g}$ daily. Pressor changes were similar in all patients irrespective of drugs taken or degree of coronary artery disease.

\section{Comment}

This study is the first to report pressor effects after the administration of $200 \mu \mathrm{g}$ thyrotrophin releasing hormone. ${ }^{4}$ The short duration of the response may account for the previous failure to show such effects by non-invasive methods. Nausea often occurs during testing with thyrotrophin releasing hormone and may offset some of the pressor effects. None of our patients experienced nausea, presumably because of the amount of premedication, though this itself may have affected the degree of the response. The premedication allowed stable baseline readings, and the absence of nausea and retching allowed clean pressure traces.

The mechanism of the pressor effects is uncertain: raised catecholamine 